\title{
Padrão de fermentação e composição química de silagens de grãos úmidos de milho e sorgo submetidas ou não a inoculação microbiana
} \author{
Andréa Roberto Duarte Lopes de Souza ${ }^{4}$, Fabíola Cristiane Alves Davy ${ }^{4}$, Tiago Zanetti \\ Albertini $^{4}$, Ciniro Costa ${ }^{5}$, Beatriz Lempp ${ }^{2}$, Clóves Cabreira Jobim ${ }^{6}$ \\ ${ }^{1}$ Pós-Graduação em Zootecnia da UNESP - Botucatu, SP. \\ 2 Pós-Graduação em Ciência Animal da Universidade Federal de Mato Grosso do Sul, Campo Grande, MS. \\ 3 Pós-Graduação em Desenvolvimento Local da Universidade Católica Dom Bosco, Campo Grande, MS. \\ ${ }^{4}$ Graduação da Universidade Federal de Mato Grosso do Sul, Campo Grande, MS. \\ ${ }^{5}$ Pós-Graduação em Zootecnia da UNESP - Botucatu, SP. \\ ${ }^{6}$ Pós-Graduação em Zootecnia da Universidade Estadual de Maringá, PR.
}

Camila Celeste Brandão Ferreira Ítavo1, Maria da Graça Morais², Luís Carlos Vinhas Ítavo³,

RESUMO - Objetivou-se avaliar o padrão de fermentação e a composição química de silagens de grãos úmidos de milho e de sorgo confeccionadas com ou sem o uso de inoculante microbiano. Avaliou-se, no experimento 1, a silagem de grãos úmidos de milho e, no experimento 2, a silagem de grãos úmidos de sorgo. O material foi ensilado em silos experimentais de PVC (50 cm de comprimento e $100 \mathrm{~mm}$ de diâmetro), três por tratamento (tempo de armazenagem, com ou sem inoculante) para cada grão. Amostras foram tomadas antes (0) e aos 1, 2, 3, 4, 8, 16, 32 e 64 dias após a ensilagem, totalizando 48 silos experimentais para cada grão. Os tratamentos foram arranjados em delineamento inteiramente casualizado, em esquema fatorial $2 \times 9$ (com e sem inoculante microbiano, nove tempos de armazenagem), com três repetições para cada grão. Não houve efeito da inoculação e do tempo pós-ensilagem sobre o teor de MS dos grãos úmidos de milho e de sorgo, com médias de 64,13 e 64,03\% e de 67,66 e $67,48 \%$ para silagens controle e inoculadas, respectivamente. Não houve efeito da inoculação sobre o $\mathrm{pH}$ dos grãos úmidos de milho e de sorgo aos 64 dias após ensilagem, com médias de 3,97 e 3,92 e de 3,94 e 3,95 unidades para silagens controle e inoculadas, respectivamente. O inoculante microbiano não promoveu alterações na composição química nem redução de perdas da MS nas silagens de grãos úmidos de milho e de sorgo. Nas condições estudadas, não é necessária inoculação para melhoria nos padrões fermentativos de silagens de grãos úmidos de milho e de sorgo.

Palavras-chave: inoculante, Lactobacillus plantarum, perdas de MS

\section{Effect of microbial inoculation on the fermentative parameters and chemical composition of high moisture corn and sorghum grain silages}

\begin{abstract}
Two experiments were run to evaluate the pattern of fermentation and the chemical composition of high moisture corn and sorghum grain silages, with or without microbial inoculation. Experiment 1 dealt with corn grain and experiment 2 dealt with sorghum grain. In each experiment, the experimental treatments resulted from a $2 \times 9$ factorial arrangement (2 levels of inoculation and 9 fermentation times: $0,1,2,3,4,4,8,16,32$ and 64 days). The experimental design was completely randomized with 3 replications. The material was ensiled in experimental silos of PVC (50 cm length and $100 \mathrm{~mm}$ diameter). Samples were taken before ( 0 ) and after 1, 2, 3, 4, 8, 16, 32 and 64 days of ensilage. There was no effect of inoculation and days of fermentation on the DM content of high moisture corn grain silages, with averages of 64.13 and $64.03 \%$, and of high moisture sorghum grain, with averages of 67.66 and $67.48 \%$, for control and inoculated silages, respectively. There was no effect of inoculation on the silages $\mathrm{pH}$, after 64 days of ensilage of corn and sorghum grain, with averages of 3.97 and 3.92 and 3.94 and 3.95 unities, for control and inoculated silages, respectively. The microbial inoculation of high moisture corn and sorghum grain did not promote alterations neither in the chemical composition nor In the DM losses. The fermentative pattern of high moisture corn and sorghum grain silages did not respond to the inoculation treatment under the studied conditions.
\end{abstract}

Key Words: DM losses, microbial inoculation, Lactobacillus plantarum

\section{Introdução}

A silagem de grãos úmidos representa uma alternativa de armazenamento de cereais na propriedade. Segundo
Henderson (1993), a conservação na forma de silagem depende da fermentação natural dos açúcares a ácidos, principalmente láctico e acético, por bactérias lácticas homo e heterofermentativas sob condições anaeróbicas. 
McDonald (1981) citou algumas características ideais da massa a ser ensilada para sua boa preservação em forma de silagem: elevado nível de substrato fermentescível na forma de carboidratos solúveis, capacidade tamponante relativamente baixa e adequado teor de matéria seca. Entretanto, nem todo material possui estes requisitos, tornando necessário em muitos casos o pré-tratamento, como o uso de aditivos.

O objetivo original do uso de aditivos é garantir que bactérias lácticas dominem a fermentação, resultando em uma silagem bem conservada (McDonald, 1981; Van Soest, 1994). Os inoculantes microbianos são seguros para o manuseio e fornecem população adicional de bactérias lácticas homofermentativas. Henderson (1993) afirmou que o aumento da taxa de fermentação por meio da inoculação de microrganismos resulta na supressão da proteólise, na deaminação e em maior retenção de carboidratos solúveis na silagem. Segundo Vilela (1998), a eficiência de inoculantes de silagem depende da população de bactérias existentes na cultura, do poder tampão e da quantidade e qualidade dos microrganismos adicionados à cultura.

Diante da intensificação da produção animal, o emprego da tecnologia da ensilagem de grãos úmidos pode contribuir significativamente para melhoria dos índices de produtividade, destacando-se a importância econômica deste alimento como constituinte de rações, de grande relevância para a redução do custo de produção (Jobim et al., 2001).

Jobim \& Reis (2001)e Costa et al.(1999) citaram inúmeras vantagens na ensilagem de grãos úmidos: maximização do uso da terra por meio da colheita antecipada; redução de perdas quantitativas e qualitativas no campo pelo menor tombamento de plantas e ataque de pássaros, insetos e doenças; e armazenagem, além de economia com a eliminação das etapas de pré-limpeza e secagem, necessárias quando do uso de grãos secos.

Grãos úmidos apresentam bom potencial para utilização no processo de ensilagem. Entretanto, Jobim \& Reis (2001), em sua revisão, demonstraram algumas desvantagens, visto que o material ensilado não possui flexibilidade de comercialização, é sensível à deterioração aeróbia e necessita de mistura diária dos ingredientes na composição da dieta.

Existem poucos trabalhos realizados no Brasil para avaliação do uso de inoculantes microbianos em silagens de grãos úmidos de cereais. Recentemente, Ítavo et al. (2003) verificaram que a inoculação de silagens de grãos úmidos de milho não influenciou o padrão de fermentação, mas diminuiu o teor de nitrogênio amoniacal e as perdas de matéria seca, indicando que a decisão sobre sua utilização depende de avaliação econômica.

Entretanto, no Canadá, Sebastian et al. (1996) analisaram, antes e aos 7, 21, 42, 138 e 202 dias após a ensilagem, os efeitos do ácido propiônico e do inoculante bacteriano em silagens de grãos úmidos de milho e notaram que a inoculação melhorou a qualidade da silagem, alterando o pH e as concentrações de ácido láctico, com valores de 4,64; 4,04 e 4,32 e 1,26; 1,87 e 1,36\%, respectivamente, para silagens adicionadas de ácido propiônico ou inoculante e silagem controle.

Schaefer et al. (1989) estudaram a inoculação de silagens da parte aérea e de grãos úmidos de milho e verificaram maiores efeitos da adição de inoculante sobre a contagem microbiológica nas silagens de grãos úmidos. Contudo, não detectaram efeitos sobre a qualidade nutricional.

Phillip \& Fellner (1992) testaram vários inoculantes na ensilagem de grãos úmidos de milho e não encontraram efeito dos tratamentos na manutenção dos teores de matéria seca e nitrogênio amoniacal, entretanto, constataram que combinações de inoculante favoreceram maiores produções de ácido láctico e que um dos inoculantes testados promoveu menor $\mathrm{pH}$ entre as silagens.

Em Mato Grosso do Sul e em todo o país, tem-se utilizado em muitas propriedades a técnica de ensilagem de grãos úmidos de cereais, com e sem o uso de inoculante microbiano. Neste sentido, torna-se importante o estudo acerca da necessidade e das conseqüências do uso de inoculação, pois consiste em mais um item de despesa operacional dentro do processo produtivo.

Neste contexto, avaliaram-se o padrão de fermentação e a composição química de grãos úmidos de milho e de sorgo, com ou sem o uso de inoculante microbiano, em função do tempo após a ensilagem.

\section{Material e Métodos}

O experimento para avaliação das silagens de grãos úmidos de milho foi realizado nas dependências da Universidade Federal de Mato Grosso do Sul - UFMS, em Campo Grande-MS, nos meses de março a outubro de 2003. O plantio do milho safrinha foi feito em março de 2003 e a colheita e ensilagem, em julho do mesmo ano, na Fazenda Paquetá Cedro, em Antonio João - MS.

O milho foi colhido com colhedeira na fase de maturação fisiológica do grão $(63,97 \%$ de MS) e processado em triturador, de acordo com o manejo da propriedade.

O experimento para avaliação de silagens de grãos úmidos de sorgo foi realizado nas dependências da Universidade 
Federal de Mato Grosso do Sul - UFMS, em Campo GrandeMS, nos meses de março a outubro de 2003. O plantio do sorgo (cv. Rancheiro) foi feito em março de 2003 e a colheita e ensilagem, em julho do mesmo ano, na Fazenda Santa Mônica, em Terenos - MS.

O sorgo foi colhido com colhedeira na fase de maturação fisiológica do grão $(69,56 \%$ de $\mathrm{MS})$ e processado em desintegradora, conforme o manejo da propriedade.

O inoculante foi adicionado nas silagens específicas após o processamento, de forma homogênea, por aspersão, de acordo com as recomendações do fabricante (100 g de inoculante para cada $50 \mathrm{t}$ de material, diluído em $100 \mathrm{~L}$ de água, ou seja $2 \mathrm{~L} / \mathrm{t}$ de material), não sendo adicionada água nas silagens controle. $\mathrm{O}$ inoculante microbiano utilizado foi o Biomax ${ }^{\circledR}$ milho e sorgo, da Katec, composto por Lactobacillus plantarum e enzimas amilolíticas.

O material processado foi ensilado em silos experimentais de PVC (50 cm de comprimento e $100 \mathrm{~mm}$ de diâmetro), com capacidade de aproximadamente $3,0 \mathrm{~kg}$. Os silos eram providos de válvulas do tipo "Bunsen", de forma a impedir a entrada de ar e permitir o livre escape dos gases da fermentação. Foram utilizados três silos laboratoriais por tempo de armazenagem, com ou sem inoculante, totalizando 48 silos para cada espécie de grão.

Os microsilos foram mantidos à sombra, em temperatura ambiente. Amostras foram tomadas antes (0) e aos 1, 2, 3, 4, $8,16,32$ e 64 dias após a ensilagem, para a determinação da curva de fermentação de cada silagem. Os silos foram pesados ao enchimento e, posteriormente, a cada tempo de avaliação, para estimação das perdas de MS durante o processo fermentativo.

Após a abertura dos silos, procedeu-se à determinação do pH, em água, de cada silagem (Silva \& Queiroz, 2002). Posteriormente, amostras foram retiradas, devidamente identificadas e congeladas para análises, realizadas no Laboratório de Nutrição Animal da UFMS, para determinação do N-amoniacal, segundo Playne \& McDonald (1966), da capacidade tampão (CT) e dos teores de MS, PB, MO, EE, FDA NIDA, conforme procedimentos descritos por Silva \& Queiroz(2002).

Os tratamentos foram arranjados em delineamento inteiramente casualizado, em esquema fatorial $2 \times 9$ (com e sem inoculante microbiano, nove tempos de armazenagem), com três repetições, totalizando 54 amostras para cada espécie. $\mathrm{O}$ modelo estatístico adotado foi:

$$
\mathrm{Y}_{\mathrm{ijk}}=\mu+\mathrm{A}_{\mathrm{i}}+\mathrm{T}_{\mathrm{j}}+\mathrm{AT}_{\mathrm{ij}}+\varepsilon_{\mathrm{ijk}}
$$

em que $Y_{i j k}=$ observação $\mathrm{k}$, referente ao inoculante $\mathrm{i}$, com armazenagem no tempo $\mathrm{j} ; \mu=$ constante geral; $\mathrm{A}_{\mathrm{i}}=$ efeito do inoculante $i, i=1$ e $2 ; T_{j}=$ tempo de armazenagem $j, j=0, \ldots$,
64; $\mathrm{AT}_{\mathrm{ij}}=$ interação inoculante $\mathrm{i}$ versus tempo de armazenagem $\mathrm{j} ; \varepsilon_{\mathrm{ijk}}=$ erro aleatório associado a cada observação $\mathrm{Y}_{\mathrm{ijk}}$.

Os dados foram avaliados por meio de análises de variância e regressão, utilizando-se o Sistema de Análises Estatísticas e Genéticas - SAEG (UFV, 2000). As médias foram comparadas pelo teste Tukey, a 5\% de significância. Os modelos estatísticos foram escolhidos de acordo com a significância dos coeficientes de regressão, pelo teste t a $5 \%$, e de determinação $\left(\mathrm{r}^{2}\right)$ e com o fenômeno biológico estudado.

O teste foi utilizado para verificar a identidade dos modelos de regressão ajustada, em função dos dias após a ensilagem, segundo Regazzi (1993), a 1\% de significância.

O modelo matricial utilizado foi:

$$
\underline{Y}=X \underline{\beta}+\varepsilon,
$$

em que $\mathrm{Y}=$ vetor dos valores observados $(\mathrm{N} \times 1) ; \mathrm{X}=$ matriz correspondente aos valores das variáveis independentes $(\mathrm{N} \times \mathrm{PH}) ; \underline{\beta}=$ vetor de parâmetros desconhecidos $(\mathrm{PH} \times 1)$; $\varepsilon=$ vetor dos erros aleatórios ( $\mathrm{N} \times 1)$, em que $\varepsilon \sim \mathrm{N}\left(\phi, \mathrm{I}^{2}\right)$; $\mathrm{P}=$ número de parâmetros do modelo, incluindo b0; $\mathrm{e}$ $\mathrm{N}=$ número total de observações, considerando $\mathrm{H}$ modelos.

\section{Resultados e Discussão}

\section{Experimento 1 - Avaliação de silagens de grãos úmidos de milho}

Os teores médios de MS, PB, MO, EE, FDA e NIDA dos grãos úmidos de milho, em função dos dias após a ensilagem e do uso de inoculante, são apresentados na Tabela 1.

Não houve efeito dos dias após ensilagem para a maioria das variáveis de composição química estudadas. Neste caso, optou-se pela discussão dos valores médios apresentados pelo parâmetro avaliado. Não se observou efeito da inoculação sobre o teor de MS das silagens ( $\mathrm{P}>0,05)$, com médias de 64,13 e 64,03\% para grãos úmidos de milho controle e inoculados, respectivamente. Sebastian et al. (1996) também não encontraram diferença na MS de silagens de grãos úmidos de milho inoculadas (média de 74,45\%).

Os valores de MS obtidos neste experimento são ligeiramente superiores aos de 63,9 e $61,4 \%$ encontrados por Jobim etal.(1997)e DeBrabanderetal.(1992), respectivamente, em silagens de grãos úmidos de milho, e inferiores aos 66,7; 71,9 e 73,7\% de MS obtidos por Reis et al. (2001), Petit \& Santos (1996) e Santos et al. (2002), respectivamente.

Os teores de $\mathrm{PB}$ dos grãos úmidos de milho ensilados sofreram influência $(\mathrm{P}<0,05)$ do inoculante durante o período de avaliação, com médias de 6,96 e 7,35\% para silagens controle e inoculadas, respectivamente (Tabela 1). 
Tabela 1 - Composição química e equações de regressão ajustadas das variáveis avaliadas em silagens de grãos úmidos de milho em função do tempo após a ensilagem e do uso de inoculante

Table 1 - Chemical composition and regression equations adjusted of evaluated variables of corn grain high moisture silages in function of the time after ensilage and of the use of inoculant

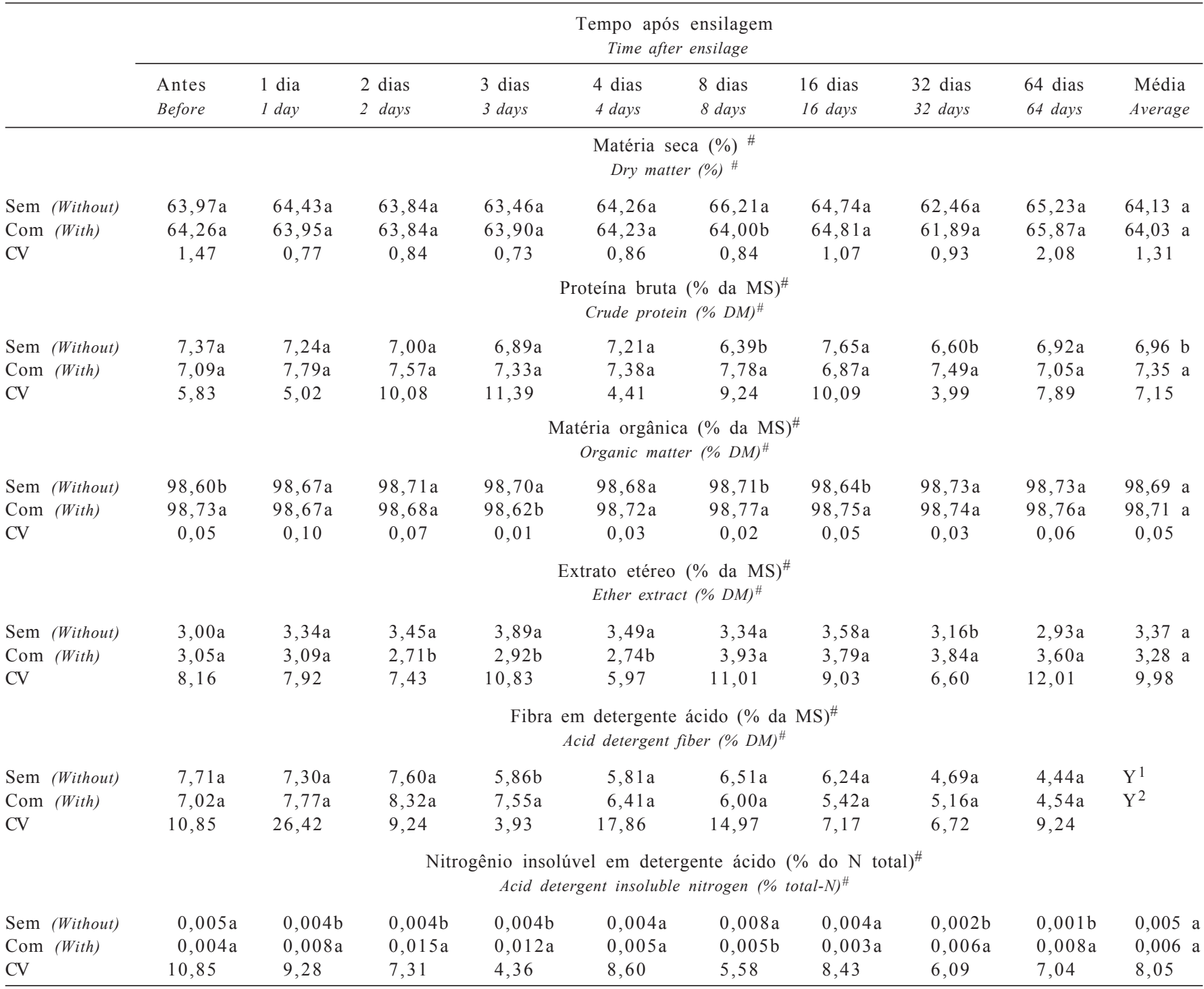

\# Médias seguidas por letras iguais na mesma coluna não diferem entre si pelo teste Tukey $(P>0,05)$ na comparação de silagens sem versus com inoculante microbiano.

\# Means followed by same letters in the same collumn didn't differ by Tukey test ( $P>0.05)$, in comparison without versus with microbial inoculant.

$1 \hat{Y}=7,02161-0,0469259 . d\left(r^{2}=0,72\right)(P<0,01)$

$2 \hat{Y}=7.02161-0.0469259 . d\left(r^{2}=0.72\right)(P<0.01)$

Sebastian et al. (1996) não notaram diferenças na PB com a inoculação de silagens de grãos úmidos de milho (média de 7,31\%). Entretanto, Schaefer et al. (1989) também registraram diferenças significativas entre silagens de grãos úmidos de milho, inoculadas ou não, com médias de 9,9 e $10,2 \%$, respectivamente. Possivelmente, a massa microbiana adicionada via inoculação favoreceu a ocorrência de maiores teores de PB nas silagens inoculadas.

As médias de $\mathrm{PB}$ observadas neste ensaio são inferiores às descritas por Jobim etal. (1997), DeBrabander et al.(1992), Reis et al. (2001) e Petit \& Santos (1996), de 10,0; 11,4; 10,2 e 9,3\%, respectivamente. Entretanto, são semelhantes à de 7,69\% relatada por Santos et al. (2002). Diferenças entre variedades, características edafo-climáticas, porcentagem de sabugo na massa ensilada e época do plantio e da colheita provavelmente foram responsáveis pelas variações na composição química.

Em decorrência dos dias após a ensilagem, não houve equações de regressão significativas ajustadas para as variáveis estudadas, o que era esperado, pois o conteúdo de nutrientes tende a permanecer inalterado na massa ensilada, principalmente em materiais que não favorecem a produção de efluentes, como os grãos úmidos de cereais. Todavia, os teores de FDA, em função do tempo após a ensilagem, apresentaram equação de regressão ajustada 
significativa comum a ambos os tratamentos, com comportamento linear decrescente, o que poderia estar relacionado à ocorrência de hidrólise ácida da celulose.

Os valores de MO não evidenciaram influência do inoculante, destacando-se com médias, durante o período de avaliação, de 98,69 e $98,71 \%$ para silagens controle e inoculadas, respectivamente, equivalentes aos $99,1 \%$ obtidos por Reis et al. (2001).

Não houve efeito $(\mathrm{P}>0,05)$ do inoculante sobre o EE, com médias, durante o período de avaliação, de 3,37 e 3,28\%, para silagens controle e inoculadas, respectivamente. DeBrabander etal.(1992)e Reis etal.(2001)obtiveram valores deEEsuperiores aos deste experimento, de 4,3 e 4,8\%, respectivamente.

Os teores de FDA não diferiram ( $\mathrm{P}>0,05)$ entre as silagens controle e inoculadas, com média estimada de 4,02\%. Também Schaefer et al. (1989) não encontraram diferenças na FDA com a inoculação, com média de $3,4 \%$ para silagens de grãos úmidos de milho no 55으 dia após ensilagem. Os valores de FDA obtidos neste experimento foram superiores aos 2,5; 3,6 e 3,95\% obtidos por Reis et al. (2001), Petit \& Santos (1996) e Santos et al. (2002). Provavelmente, a maior proporção de sabugo na massa ensilada contribuiu para os teores de FDA superiores neste ensaio.

Não houve equações de regressão significativas para NIDA em função dos dias após ensilagem. As concentrações de NIDA não diferiram entre as silagens de grãos úmidos de milho inoculadas ou não $(\mathrm{P}>0,05)$, de modo que os valores alcançados não comprometeram a qualidade nutricional da silagem, visto que as médias, para silagens controle e inoculadas, foram de 0,005 e $0,006 \%$ do N-total, respectivamente. Provavelmente, as boas práticas de ensilagem adotadas, como rápido enchimento e boa compactação, contribuíram para os baixos teores de NIDA, em razão da expulsão do oxigênio e do início da fermentação láctica (Tabela 2) em função dos dias após ensilagem. Entretanto, valores superiores foram obtidos por Schaefer et al. (1989), que não verificaram diferenças com a inoculação de silagens de grãos úmidos de milho, registrando médias de 3,1 e 2,7\% do N-total para silagens inoculadas e controle, respectivamente. Talvez a utilização por Schaefer et al. (1989) de silos de concreto, de maior capacidade que os silos deste ensaio, possa ter favorecido a ocorrência de maiores teores de NIDA.

Os valores de $\mathrm{pH}$, a capacidade tamponante, o nitrogênio amoniacal, a razão nitrogênio amoniacal:nitrogênio total e as perdas de MS dos grãos úmidos de milho, conforme o tempo após a ensilagem e o uso de inoculante, são descritos na Tabela 2.

Após a verificação da identidade dos modelos de regressão (Regazzi, 1993), observou-se similaridade entre

Tabela 2 - Equações de regressão ajustadas dos parâmetros fermentativos avaliados das silagens de grãos úmidos de milho conforme o tempo após a ensilagem (dias) e o uso de inoculante

Table 2 - Regression equations adjusted of evaluated fermentative parameters of corn grain high moisture silages in function of the time (days) after ensilage and of the use of inoculant

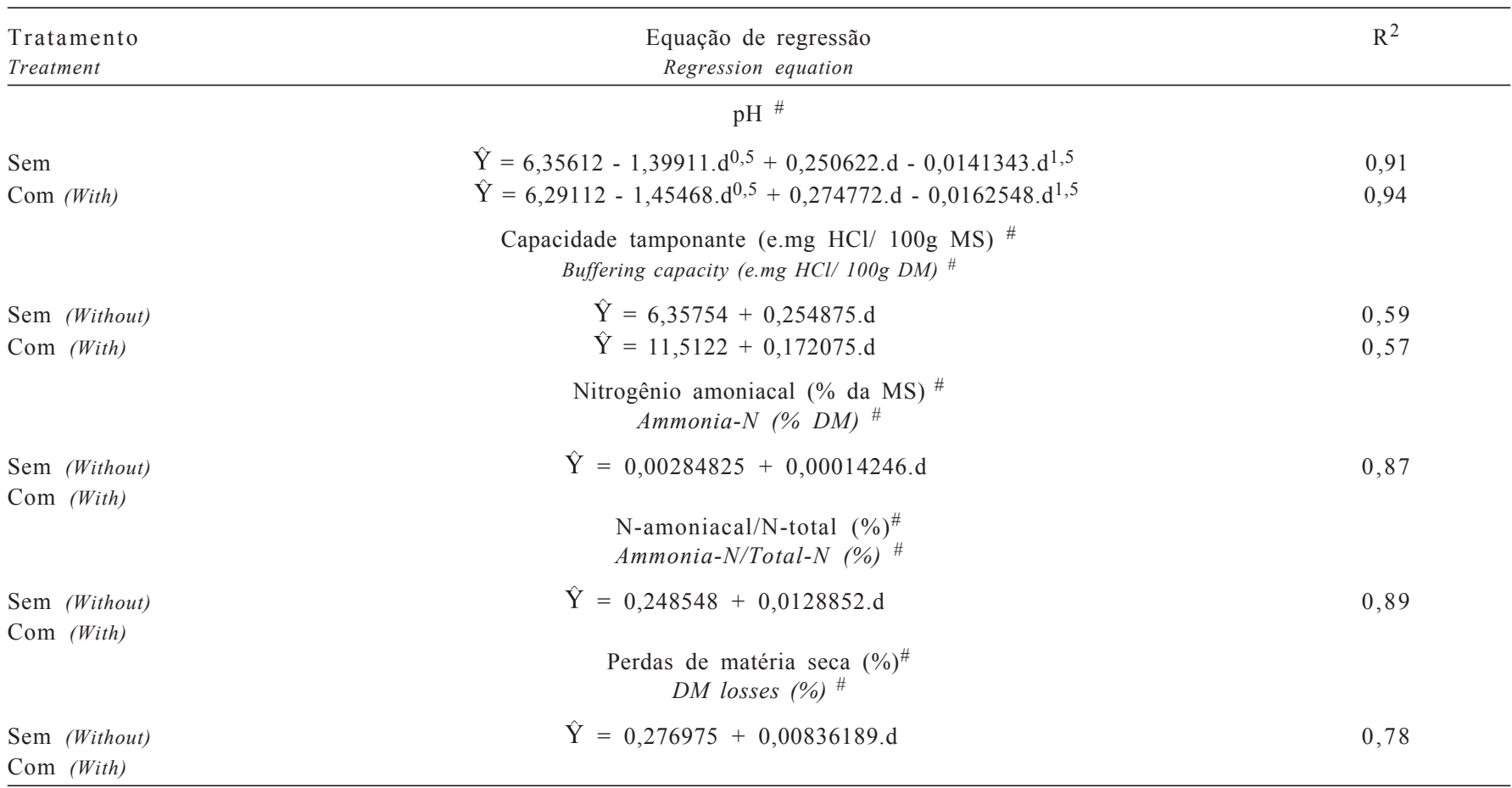

$\#(\mathrm{P}<0,01)(P<0.01)$ 
os modelos de regressão ajustada, de acordo com os dias após ensilagem, para os parâmetros capacidade tamponante, $\mathrm{N}$-amoniacal, razão N-amoniacal:N-total e perdas de MS. Nestes casos, optou-se pela apresentação de equações de regressão comuns, o que indica que não houve efeito da inoculação sobre estes parâmetros.

Houve efeito do tempo após a ensilagem para as variáveis $\mathrm{pH}$, capacidade tamponante e perdas de MS. Os valores de $\mathrm{pH}$ das silagens de grãos úmidos de milho, aos 64 dias, estimados a partir das equações de regressão ajustadas, foram de 3,97 e 3,92 unidades, para silagens controle e inoculadas, respectivamente, similares aos obtidos por Phillip \& Fellner (1992), de 3,91 e 3,93 unidades, e por Petit \& Santos (1996), de 3,9 unidades. Schaefer et al. (1989) também não encontraram diferenças no $\mathrm{pH}$ de silagens de grãos úmidos de milho inoculadas ou não, com média de 5,5, atribuída ao alto teor de MS dos grãos. Sebastian et al. (1996), no entanto, constataram que a inoculação favoreceu a redução do pH de silagens de grãos úmidos de milho, com médias de 4,32 e 4,07 para silagens controle e inoculadas, respectivamente.

Ressalta-se que todos os valores de $\mathrm{pH}$ obtidos neste ensaio a partir do sexto dia após a ensilagem foram de 4,22 e 4,14, respectivamente, para silagens controle e inoculadas, dentro da faixa ideal $(3,8$ a 4,2). As equações de regressão para a variável $\mathrm{pH}$, de silagens inoculadas ou não, indicam estabilização de $\mathrm{pH}$ após o processo fermentativo inicial, o que corrobora os relatos de McDonald (1991), da existência de um período de queda de $\mathrm{pH}$, seguido de estabilização, por volta de sete dias após a ensilagem.

Sebastian et al. (1996) pesquisaram o efeito do uso de aditivos em silagens de grãos úmidos de milho sobre o $\mathrm{pH}$ das silagens e revelaram que a taxa de declínio de $\mathrm{pH}$ pareceu maior para a silagem inoculada, indicando que o aporte adicional de microrganismos foi responsável pela potencialização da fermentação dos carboidratos presentes na biomassa.

As equações de regressão para capacidade tamponante demonstram comportamento linear positivo, explicado pela diminuição de $\mathrm{pH}$, pois essa variável consiste na capacidade do material em resistir às alterações de $\mathrm{pH}$.

Os valores de $\mathrm{N}$-amoniacal e a razão $\mathrm{N}$-amoniacal: $\mathrm{N}$-total não sofreram efeito da inoculação. As silagens de grãos úmidos de milho, controle e inoculadas, apresentaram valores médios, aos 64 dias, de 0,012 e 1,32\% para variáveis $\mathrm{N}$-amoniacal e razão $\mathrm{N}$-amoniacal:N-total, respectivamente. Os valores estimados foram inferiores aos 2,7\% do N-total encontrados por DeBrabander et al. (1992).

Embora nenhum efeito $(\mathrm{P}>0,01)$ do inoculante tenha sido observado para as variáveis $\mathrm{N}$-amoniacal e relação
$\mathrm{N}$-amoniacal:N-total, verificou-se aumento com o passar dos dias após ensilagem, conforme demonstrado pelas equações de regressão ajustadas (Tabela 3). Sebastian et al. (1996) também não encontraram efeito dos tratamentos sobre os teores de $\mathrm{N}$-amoniacal, com médias de 5,05 e 4,68\% MS para silagens de grãos úmidos de milho inoculadas e controle, respectivamente. Os autores encontraram, no entanto, aumento em função dos dias após a ensilagem.

A equação de regressão ajustada para perdas de MS dos grãos úmidos de milho não sofreu efeito da inoculação ( $\mathrm{P}<0,01$ ), com média de $0,81 \%$ para silagens, inoculadas ou não, aos 64 dias após ensilagem. A equação de regressão comum para silagens, inoculadas ou não, apresentou comportamento linear positivo, entretanto, a proporção de perdas foi pequena, o que poderia indicar a ocorrência de perdas inevitáveis do processo, como a causada pela respiração vegetal (McDonald, 1981).

Essas observações confirmam os relatos de Ítavo et al. (2003), que não notaram melhora na fermentação com a inoculação, mas obtiveram menores teores de $\mathrm{N}$-amoniacal e perdas de MS com o uso de inoculantes na ensilagem de grãos úmidos de milho. Da mesma forma, Phillip \& Fellner (1992) constataram que a inoculação não melhorou o padrão de fermentação de silagens de grãos úmidos de milho.

Os teores de MS, PB, MO, EE, FDA e NIDA dos grãos úmidos de sorgo, conforme o tempo após a ensilagem e o uso de inoculante, são apresentados na Tabela 3.

Não houve efeito do tempo após ensilagem para maioria das variáveis da composição química. Neste caso, optou-se pela discussão dos valores médios apresentados pelo parâmetro avaliado.

A inoculação não promoveu diferenças $(P>0,05)$, durante o período de avaliação, nos teores de MS, com médias de 67,66 e $67,48 \%$, respectivamente, para silagens controle e inoculadas, superiores aos 65,75 e $63,9 \%$ apresentados por Grigolleto et al. (2003) e Cândido et al. (2004), em silagens de grãos úmidos de sorgo.

Os teores de $\mathrm{PB}$ dos grãos úmidos de sorgo foram alterados $(\mathrm{P}<0,05)$ pelo uso de inoculante, com médias de 7,47 e $6,89 \%$, para silagens controle e inoculadas, respectivamente. Todavia, Grigolleto et al. (2003) e Cândido et al. (2004) encontraram, para silagens de grãos úmidos de sorgo, valores de 9,36 e 9,80\% de $\mathrm{PB}$, respectivamente, superiores aos obtidos neste ensaio, confirmando a teoria da diferença entre as variedades, as características edafoclimáticas e a época de plantio e colheita, visto que os grãos neste experimento foram obtidos na safrinha.

Considerando o tempo após a ensilagem, para as variáveis MS, PB, MO, EE e NIDA, não houve equações de regressão 
Tabela 3 - Composição química e equações de regressão ajustadas das variáveis avaliadas das silagens de grãos úmidos de sorgo conforme o tempo após a ensilagem e o uso de inoculante

Table 3 - Chemical composition and regression equations adjusted of evaluated variables of sorghum grain high moisture silages in function of the time after ensilage and of the use of inoculant

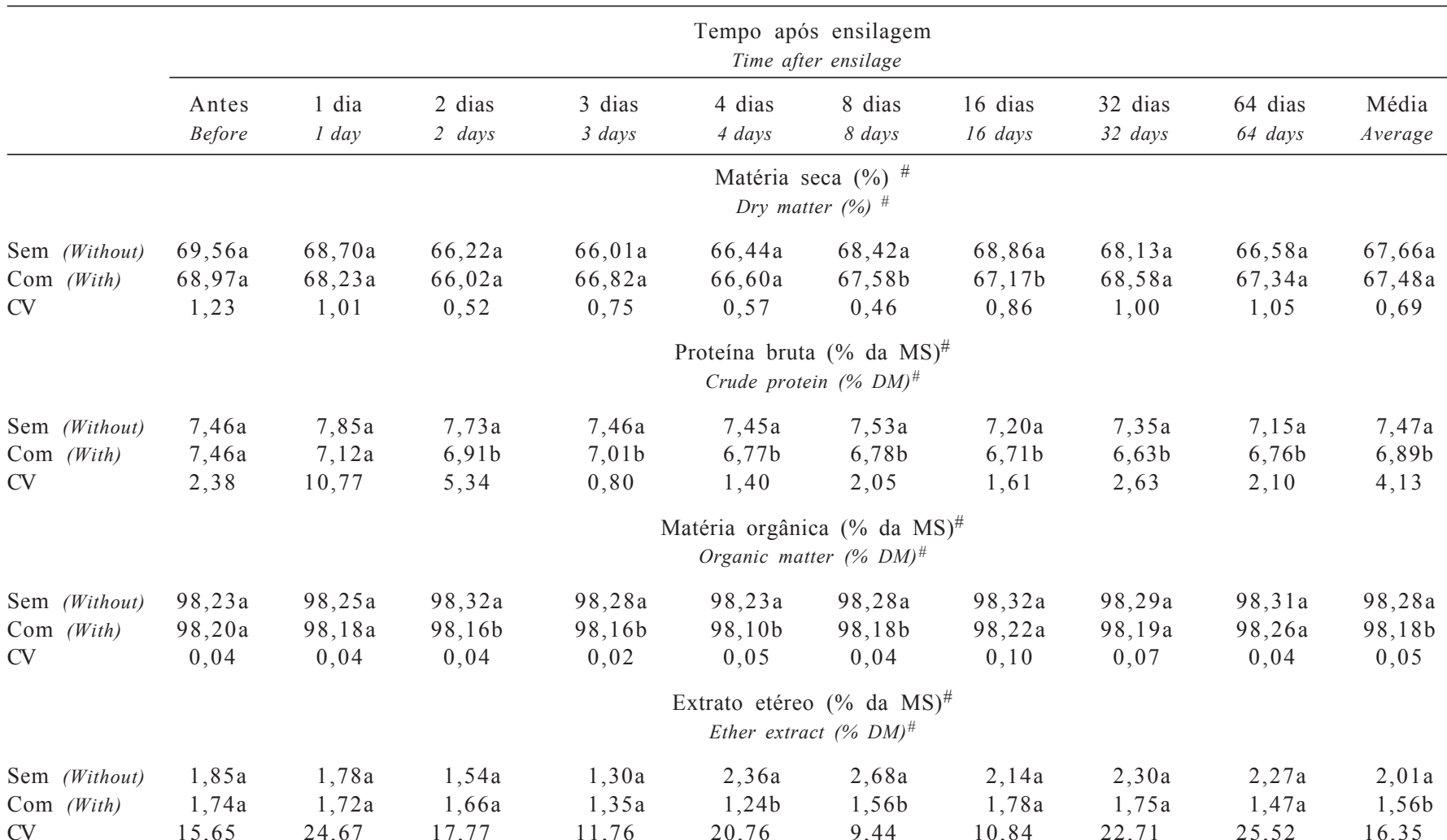

Fibra em detergente ácido $(\% \text { da } \mathrm{MS})^{\#}$ Acid detergent fiber $(\% \mathrm{DM})^{\#}$

\begin{tabular}{|c|c|c|c|c|c|c|c|c|c|}
\hline Sem (Without) & $5,71 \mathrm{a}$ & $5,79 \mathrm{a}$ & $5,37 \mathrm{a}$ & $4,94 a$ & $4,18 \mathrm{a}$ & $5,75 \mathrm{a}$ & $4,37 \mathrm{a}$ & $5,84 \mathrm{a}$ & $4,24 \mathrm{a}$ \\
\hline Com (With) & $5,34 \mathrm{a}$ & $5,75 \mathrm{a}$ & $5,62 \mathrm{a}$ & $5,39 \mathrm{a}$ & $4,68 \mathrm{a}$ & $5,18 \mathrm{a}$ & $5,14 \mathrm{a}$ & $4,98 \mathrm{a}$ & $4,62 \mathrm{a}$ \\
\hline $\mathrm{CV}$ & 6,12 & 8,91 & 8,75 & 7,54 & 6,11 & 14,50 & 9,84 & 14,34 & 8,11 \\
\hline
\end{tabular}

Nitrogênio insolúvel em detergente ácido (\% do $\mathrm{N}$ total $)^{\#}$ Acid detergent insoluble nitrogen $(\%$ total-N) \#

\begin{tabular}{|c|c|c|c|c|c|c|c|c|c|c|}
\hline Sem (Without) & $0,011 \mathrm{a}$ & $0,014 \mathrm{a}$ & $0,012 \mathrm{a}$ & $0,008 \mathrm{~b}$ & $0,006 \mathrm{a}$ & $0,015 \mathrm{a}$ & $0,007 \mathrm{a}$ & $0,015 \mathrm{a}$ & $0,007 \mathrm{a}$ & $0,01 \mathrm{a}$ \\
\hline Com (With) & $0,010 \mathrm{a}$ & $0,012 \mathrm{a}$ & $0,015 \mathrm{a}$ & $0,012 \mathrm{a}$ & $0,007 \mathrm{a}$ & $0,011 b$ & $0,010 \mathrm{a}$ & $0,010 \mathrm{~b}$ & $0,010 \mathrm{a}$ & $0,01 \mathrm{a}$ \\
\hline
\end{tabular}

\# Médias seguidas por letras iguais na mesma coluna não diferem entre si pelo teste Tukey $(P>0,05)$, na comparação de silagens com e sem inoculante microbiano.

\# Means followed by same letters in the same collumn didn't differ by Tukey test $(P>0.05)$, in comparison without versus with microbial inoculant.

$1 \hat{Y}=5,32551-0,0120733 \cdot d\left(r^{2}=0,70\right)$

$2 \hat{Y}=5.32551-0.0120733 . d\left(r^{2}=0.70\right)$

significativas, confirmando a boa estabilidade do material ensilado. Os valores médios de MO não evidenciaram influência do inoculante, com médias, durante o período de avaliação, de 98,28 e $98,18 \%$, para silagens controle e inoculadas, respectivamente, semelhantes aos $98,4 \%$ obtidos por Grigolleto et al. (2003), em silagens de grãos úmidos de sorgo.

A inoculação promoveu $(\mathrm{P}<0,05)$ diferenças nos teores de EE, com médias, durante o período de avaliação, de 2,01 e $1,56 \%$, para silagens controle e inoculadas, respectivamente.

Na avaliação da identidade de modelos de regressão, não foram detectadas diferenças entre os modelos ajustados para a FDA em função do uso de inoculante. A estimativa, aos 64 dias após ensilagem, para silagens controle e inoculadas, foi de $4,55 \%$, inferior à de $6,5 \%$ obtida por Cândido et al. (2004) em silagens de grãos úmidos de sorgo. A equação conjunta para FDA dos grãos úmidos de sorgo ensilados apresentou comportamento linear negativo em função dos dias após a ensilagem, o que pode estar relacionado à hidrólise ácida da celulose.

A inoculação não influenciou $(P>0,05)$ os teores de NIDA nas silagens de grãos de sorgo controle e inoculadas, com média, durante o período de avaliação, de $0,01 \%$ 
do N-total, o que não indica alta ocorrência do processo de caramelização (ligação carboidrato-proteína), denominado reação de Maillard, comprometendo o valor nutricional da silagem.

Os valores de $\mathrm{pH}$, capacidade tamponante, nitrogênio amoniacal, razão nitrogênio amoniacal:nitrogênio total e perdas de MS dos grãos úmidos de sorgo, em função do tempo após a ensilagem e do uso de inoculante, são apresentados na Tabela 4.

Após a verificação da identidade dos modelos de regressão (Regazzi, 1993), observou-se similaridade entre os modelos de regressão ajustada conforme os dias após ensilagem para os parâmetros capacidade tamponante, $\mathrm{N}$-amoniacal, razão N-amoniacal:N-total e perdas de MS. Nestes casos, optou-se pela apresentação de equações de regressão comuns, indicando ausência de efeito da inoculação sobre estes parâmetros das silagens.

Os valores estimados de $\mathrm{pH}$ das silagens de grãos úmidos de sorgo, aos 64 dias após ensilagem, para silagens controle e inoculadas, foram de 3,94 e 3,95 unidades, respectivamente, inferiores ao de 4,6, obtido por Cândido et al. (2004). O pH dos grãos de sorgo antes da ensilagem, inoculados ou não, diferiu $(\mathrm{P}<0,05)$, como conseqüência da operacionalidade da propriedade onde se efetuou a ensilagem. Houve demora para realização da ensilagem dos grãos de sorgo inoculados, o que provavelmente favoreceu o início da fermentação do material, promovendo diferenças nos teores de PB e MO (Tabela 3), por meio da volatilização de compostos nitrogenados. Entretanto, essa diferença não desvaloriza essas silagens, pois todos os valores a partir do terceiro dia de ensilagem permaneceram na faixa ideal de $\mathrm{pH}(3,8$ a 4,2).

Assim como para silagens de grãos úmidos de milho, as equações de regressão para a variável $\mathrm{pH}$, nas silagens de sorgo inoculadas ou não indicaram estabilização do pH após o terceiro dia de ensilagem $(\mathrm{pH}<4,2)$, corroborando os relatos de McDonald (1981), que indicaram um período de queda, seguido de estabilização, aproximadamente sete dias após a ensilagem. Segundo Van Soest (1994), o material ensilado passa por uma sequência de alterações fermentativas; no primeiro estágio, ocorre a morte da célula vegetal e a rápida exaustão do oxigênio, seguida pela proliferação bacteriana e pelo desenvolvimento de fermentação ácida.

As equações ajustadas em função dos dias após ensilagem para capacidade tamponante não diferiram $(\mathrm{P}>0,01)$. A equação comum, aos 64 dias após a ensilagem, estimou uma média de 23,48 e.mg HCl/100g MS para silagens controle e inoculadas. A equação de regressão demonstrou comportamento linear positivo, explicado pela redução do
$\mathrm{pH}$, pois essa variável consiste na capacidade do material em resistir às alterações de $\mathrm{pH}$.

As equações de regressão ajustadas conjuntas para as variáveis capacidade tamponante, $\mathrm{N}$-amoniacal, razão $\mathrm{N}$-amoniacal:N-total e perdas de matéria seca apresentaram comportamento linear positivo conforme os dias após ensilagem.

Os valores de $\mathrm{N}$-amoniacal e da razão $\mathrm{N}$-amoniacal: $\mathrm{N}$-total não foram influenciados pela inoculação, pois, no teste de identidade de modelos, não foram detectadas diferenças entre os modelos ajustados para silagens de grãos úmidos de sorgo controle e inoculadas. Assim, considerou-se um modelo comum e suas estimativas iguais estatisticamente (Tabela 4).

As equações de regressão ajustadas para as perdas de MS dos grãos úmidos de sorgo não diferiram com a inoculação $(\mathrm{P}<0,01)$. $\mathrm{Na}$ análise da equação conjunta, observou-se comportamento linear positivo, demonstrando aumento nas perdas com o passar dos dias após a ensilagem. Todavia, a magnitude das perdas foi pequena, indicando a ocorrência de perdas inerentes ao processo de ensilagem, ou seja, perdas inevitáveis, como as causadas pelo processo de respiração vegetal, citadas por McDonald (1981).

Possivelmente, os maiores valores de $\mathrm{N}$-amoniacal e de perdas da MS obtidos nas silagens de grãos úmidos de milho (Tabela 2), quando comparadas às de sorgo (Tabela 4), estão relacionadas à participação do sabugo, que pode ter prejudicado a compactação. Portanto, o artifício de aumentar o volume da massa ensilada deve ser considerado extremamente importante na ensilagem de grãos úmidos de milho, pois maiores participações de sabugo dificultam a compactação e promovem a entrada de ar entre lacunas de partículas de diferentes densidades.

Ressalta-se que a ensilagem em silos experimentais favorece a compactação, promovendo densidade adequada e facilitando o processo fermentativo. Entretanto, segundo Wernli \& Ojeda (1990), silagens produzidas em laboratório permitem a realização de todas as análises necessárias à caracterização da fermentação, às análises estatísticas, às modelagens matemáticas e ao estabelecimento do comportamento teórico dos tratamentos estudados.

Não houve efeitos positivos do uso da inoculação microbiana nas silagens de grãos úmidos de milho e sorgo, pois todas as silagens apresentaram parâmetros adequados quanto ao perfil de fermentação e à composição química. Talvez a população de bactérias lácticas epifíticas no grão tenha sido suficiente para garantir boa fermentação, o que confirma a teoria de Vilela (1998) de que o uso de silos laboratoriais favorece esse processo. Entretanto, 
Tabela 4 - Equações de regressão ajustadas dos parâmetros de fermentação avaliados nas silagens de grãos úmidos de sorgo em função do tempo após a ensilagem (dias) e do uso de inoculante

Table 4 - Regression equations adjusted of fermentative parameters evaluated of sorghum grain high moisture silages in function of the time (days) after ensilage and of the use of inoculant

\begin{tabular}{lccc}
\hline $\begin{array}{l}\text { Tratamento } \\
\text { Treatment }\end{array}$ & $\begin{array}{c}\text { Equação de regressão } \\
\text { Regression equation }\end{array}$ & $\mathrm{R}^{2}$ \\
\hline & $\mathrm{pH}{ }^{\#}$ & & \\
Sem (Without) & $\hat{\mathrm{Y}}=5,29035-1,01736 . \mathrm{d}^{0,5}+0,223362 . \mathrm{d}-0,0147094 . \mathrm{d}^{1,5}$ & \\
Com (With) & $\hat{\mathrm{Y}}=4,80760-0,541081 . \mathrm{d}^{0,5}+0,0963858 . \mathrm{d}-0,00526078 . \mathrm{d}^{1,5}$ & 0,96 & 0,95 \\
\hline
\end{tabular}

Capacidade tamponante (e.mg $\mathrm{HCl} / 100 \mathrm{~g} \mathrm{MS})^{\#}$

Buffering capacity (e.mg HCl/100g DM) \#

Sem (Without)

$$
\hat{Y}=13,8245+0,150903 \cdot d \quad 0,60
$$

Com (With)

Nitrogênio amoniacal (\% da MS) \#

Ammonia-N (\% DM) \#

Sem (Without)

$\hat{Y}=0,00265625+0,0000542629 . d \quad 0,76$

Com (With)

$$
\begin{gathered}
\mathrm{N} \text {-amoniacal/N-total }(\%)^{\#} \\
\text { Ammonia-N/Total-N (\%) }
\end{gathered}
$$

Sem (Without)

$$
\hat{Y}=0,229225+0,00505764 . d \quad 0,75
$$

Com (With)

$$
\text { Perdas de matéria seca }(\%)^{\#}
$$$$
\text { DM losses (\%) \# }
$$

Sem (Without)

Com (With)

$$
\hat{Y}=0,305606+0,00143577 . d \quad 0,72
$$

$\#(P<0,01)(P<0.01)$.

este mesmo material foi ensilado em silos-piloto, de maior capacidade, e apresentou as mesmas tendências observadas neste ensaio.

Contudo, as boas práticas de ensilagem, como o uso do correto tamanho de partícula, o rápido enchimento, a boa compactação e vedação e o adequado dimensionamento do silo, são imprescindíveis na confecção de uma silagem e não podem ser substituídas por inoculantes.

\section{Conclusões}

As silagens de grãos úmidos de milho e de sorgo, nas condições estudadas, não necessitam da inoculação para melhorar os padrões fermentativos. Apesar das diferenças numéricas, o padrão de fermentação das silagens de grãos úmidos de milho e de sorgo foi semelhante.

$\mathrm{O}$ inoculante microbiano utilizado não foi eficiente nas condições estudadas, visto que a inoculação, tanto na silagem de grãos úmidos de milho quanto na de sorgo, não melhorou a composição química nem reduziu as perdas de matéria seca.

\section{Literatura Citada}

CÂNDIDO, M.J.D.; POMPEU, R.C.F.F.; PITOMBEIRA, J.B. et al. Valor nutritivo e características fermentativas de silagens de grãos úmidos de sorgo (Sorghum bicolor L. Moench). In: REUNIÃO ANUAL DA SOCIEDADE BRASILEIRA DE ZooteCniA, 41., 2004, Campo Grande. Anais... Campo Grande:Sociedade Brasileira de Zootecnia, [2004] CD-ROM. Forragicultura. FOR-335.

COSTA, C.; ARRIGONI, M.D.B.; SILVEIRA, A.C. et al. Silagem de grãos úmidos. In: SIMPÓSIO SOBRE NUTRIÇÃO DE BOVINOS, 7., 1999, Piracicaba. Anais... Piracicaba: Fundação de Estudos Agrários Luiz de Queiroz, 1999. p.69-87.

DeBRABANDER, D.L.; COTTYN, B.G.; BOUCQUE, C.H.V. Substitution of concentrates by ensiled high moisture maize grain in dairy cattle diets. Animal Feed Science and Technology, v.38, p.57-67, 1992.

GRIGOLLETO, L.C.; FURLAN, A.C.; MURAKAMI, A.E. et al. Valor nutritivo da silagem de grãos úmidos de sorgo de alto ou baixo conteúdo de taninos para frango de corte. In: REUNIÃO ANUAL DA SOCIEDADE BRASILEIRA DE ZOOTECNIA, 40., 2003, Santa Maria. Anais... Santa Maria: Sociedade Brasileira de Zootecnia, [2003]. CD-ROM. Nutrição de ruminantes. NNR 25.

HENDERSON, N. Silage additives. Animal Feed Science and Technology, v.45, p.35-56, 1993.

ÍTAVO, C.C.B.F.; MORAIS, M.G.M.; ÍTAVO, L.C.V. et al. Parâmetros fermentativos de silagens de grãos úmidos de milho com ou sem o uso de aditivo microbiano. In: REUNIÃO ANUAL 
DA SOCIEDADE BRASILEIRA DE ZOOTECNIA, 40., 2003, Santa Maria. Anais... Santa Maria:Sociedade Brasileira de Zootecnia, [2003]. CD-ROM. Forragicultura. FOR-248.

JOBIM, C.C.; CECATO, U.; CANTO, M.W. Utilização de silagem de grãos de cereais na alimentação animal. In: SIMPÓSIO SOBRE PRODUÇÃO E UTILIZAÇÃO DE FORRAGENS CONSERVADAS, 1., 2001, Maringá. Anais... Maringá:CCA/ UEM/DZO, 2001. p.146-176.

JOBIM, C.C.; REIS, R.A. Produção e utilização de silagem de grãos úmidos de milho. In: REUNIÃo ANUAL DA SOCIEDADE BRASILEIRA DE ZOOTECNIA, 38., 2001, Piracicaba. Anais... Piracicaba:Sociedade Brasileira de Zootecnia, 2001. p.912-927.

JOBIM, C.C.; REIS, R.A.; RODRIGUES, L.R.A. et al. Avaliação das silagens de grãos úmidos de milho (Zea mays L.). Pesquisa Agropecuária Brasileira, v.32, n.3, p.311-31, 1997.

McDONALD, P. The biochemistry of silage. New York: John Wiley, 1981. 207p.

PETIT, H.V.; SANTOS, G.T. Milk yield and composition of dairy cows fed concentrate based on high moisture wheat or high moisture corn. Journal of Dairy Science, v.79, p.2292-2296, 1996.

PHILLIP, L.E.; FELLNER, V. Effects of bacterial inoculation of high-moisture ear corn on its aerobic stability, digestion, and utilization for growth by beef steers. Journal of Animal Science, v.70, p.3178-3187, 1992.

PLAYNE, M.J.; McDONALD, P. The buffering constituints of herbage and silage. Journal of Science Food Agriculture, v. 17 , p. $262-268,1966$.

REGAZZI, A.J. Teste para verificar a identidade de modelos de regressão e igualdade de alguns parâmetros num modelo polinomial ortogonal. Revista Ceres, v.40, n.228, p.176$195,1993$.

REIS, W.; JOBIM, C.C.; MACEDO, F.A.F. et al. Desempenho de cordeiros terminados em confinamento, consumindo silagens de milho de grãos de alta umidade ou grãos de milho hidratados em substituição aos grãos de milho seco da dieta. Revista Brasileira de Zootecnia, v.30, n.2, p.596-603, 2001.
SANTOS, C.P.; FURTADO, C.E.; JOBIM, C.C. et al. Avaliação da silagem de grãos úmidos de milho na alimentação de equinos em crescimento: valor nutricional e desempenho. Revista Brasileira de Zootecnia, v.31, n.3, p.1214-1222, 2002.

SCHAEFER, D.M.; BROTZ, P.G.; ARP, S.C. et al. Inoculation of corn silage and high moisture corn with lactic acid bacteria and its effects on the subsequent fermentations and on feedlot performance of beef steers. Animal Feed Science and Technology, v.25, p.23-38, 1989.

SEBASTIAN, S.; PHILIP, L.E.; FELLNER, V. et al. Comparative assessment of bacterial inoculation and propionic acid treatment on aerobic stability and microbial populations of ensiled highmoisture ear corn. Jounal of Animal Science, v.74, p.447456, 1996.

SILVA, D.J.; QUEIROZ, A.C. Análise de alimentos (Métodos químicos e biológicos). 3.ed. Viçosa, MG: Universidade Federal de Viçosa, 2002. 235p.

UNIVERSIDADE FEDERAL DE VIÇOSA - UFV. SAEG-Sistema de análises estatísticas e genéticas (manual do usuário). Versão 8.0. Viçosa, MG: 2000.142p.

Van SOEST, P.J. Nutritional ecology of the ruminant. 2.ed. Ithaca: Comstock Publishing Associations, 1994. 476p.

VILELA, D. Aditivos para silagem de plantas tropicais. In: REUNIÃO ANUAL DA SOCIEDADE BRASILEIRA DE ZOOTECNIA, 35., 1998, Botucatu. Anais... Botucatu: Sociedade Brasileira de Zootecnia, 1998. p.73-107.

WERNLI, C.; OJEDA, F. Recomendaciones sobre conservación y utilización de ensilajes. In: RUIZ, M.; RUIZ, A. (Eds.) Nutricíon de rumiantes: guía metodológica de investigación. San Jose: Instituto Interamericano de Cooperación para la Agricultura: Red de Investigación en Sistemas de Producción Animal em Latinoamérica, 1990. p.179-232. 